\title{
CHANGES IN ANXIETY LEVELS THROUGH THE EDUCATION YEARS IN THE MPHARM PROGRAMME
}

\author{
ISHMAIL KHALIL, HANA MORRISSEY, PATRICK BALL \\ University of Wolverhampton, School of Pharmacy, United Kingdom \\ Email: hana.morrissey@wlv.ac.uk
}

Received: 18 Apr 2019, Revised and Accepted: 26 Jun 2019

\begin{abstract}
Objective: Over 8.2 million people were affected by anxiety in the UK in 2013 and it is currently the world has most experienced mental health disorder. Previous research has indicated that a rising level of anxiety in higher education students is resulting in decreased academic success and progress. This research explores student's perceptions of whether anxiety levels change throughout their course, whether it improves or worsens from the first year to the final year in the course and its effect on academic achievements.
\end{abstract}

Methods: A survey-based approach was taken with questionnaires handed out to students in their $4^{\text {th }}$ year of the MPharm programme at the University of Wolverhampton.

Results: Fifty completed questionnaires were analysed by age, gender and ethnicity in order to identify patterns and trends. The results were in conformity with previous research findings that anxiety severity increases through education years and it is affecting educational performance and progress. There were $68 \%$ of all students who participated stated they were currently experiencing anxiety and $86 \%$ of those stating their anxiety was now worse than it was in their sixth form years. On average, participants chose a minimum of four factors that triggered anxious episodes; $36 \%$ of participants stated that anxiety affected their grades all of the time and $44 \%$ were affected during written exams only.

Conclusion: This study suggests further research into anxiety is needed to address this growing phenomenon and mechanisms are needed in order to accommodate the needs of students who are affected.

Keywords: Academic performance, Student experience, Anxiety

(c) 2019 The Authors. Published by Innovare Academic Sciences Pvt Ltd. This is an open access article under the CC BY license (http://creativecommons.org/licenses/by/4.0/) DOI: http://dx.doi.org/10.22159/ijcpr.2019v11i4.34951

\section{INTRODUCTION}

Anxiety is currently the most commonly experienced mental health illness globally [1]. Over 8.2 million people were affected in the UK in 2013 [2]. Anxiety is the feeling of being at unease due to unrealistic error, worry or fears. It may be mild, moderate, severe or disabling [3]. Anxiety in students in higher education is thought to be interfering with students' examination performance [4]. Russell and Shaw [5], found that $10 \%$ of students reported marked to severe social anxiety during higher education and recommended further research is required to explore the impact of social anxiety on students in higher education. Their study used the Liebowitz Social Anxiety Scale $(n=1007)$ and concluded that vulnerability to impaired mental health depends upon the programme of study. Another report suggested that medical students experience anxiety and depression more than other students do $(n=252)$ [6]. The study found that $60 \%(n=113)$ of students in their study had anxiety and depression $(73 \%, 66 \%, 49 \%$ and $47 \%$ of Year 1, 2, 3 and 4 respectively). Bayram and Bilgel [7] concluded that the 'high prevalence of depression, anxiety and stress symptoms among university students is alarming' and found that year 1 and year 2 students had the highest levels of anxiety and stress symptoms. This study used the Depression Anxiety and Stress Scale (DASS-42) $(n=1617)$. They found that students who were most affected by anxiety and depression were those who were most dissatisfied with the education received. The structure, delivery and quality of higher education programmes and availability of students' support services, vary widely and cannot be assumed to be the same globally or even within the UK $[5,7]$. Andrews and Wilding [8], reported anxiety and depression increased after entering higher education and was further exacerbated by financial problems and eventually led to decreased academic performance. Their study used the Hospital Anxiety and Depression Scale (HADS) [9] which was handed out to students $(n=351)$ one month before the start of their course and then again at mid-point of their course. They found that by mid-course $9 \%$ of previously symptom-free students became depressed and $20 \%$ became anxious at a clinically significant level. They reported that financial stress was one of the main causes. Mackaskill, administered a mental health questionnaire to students $(\mathrm{n}=1197)$ on their first day at university then at the end of years 1,2 and 3, they found that on admission $12.9 \%$ experienced anxiety, however, at year 2, this increased to $23.1 \%$. Another significant finding was $24.3 \%$ of females experienced anxiety compared to $12.6 \%$ of males.

\section{Aims}

The aim of this study was to explore whether anxiety levels change in students through education years in the Master of Pharmacy (MPharm) programme at the University of Wolverhampton.

\section{MATERIALS AND METHODS}

A survey-based approach was adopted for this study. The sample was pharmacy students 'in their final year of the MPharm course. Out of the total class of 69 students, 50 voluntarily participated $(72 \%)$. The only inclusion criterion was being a fourth-year MPharm students from this university. After a brief introduction explaining the purpose of the study, confidentiality and consent, the questionnaires were handed out to all students. All questionnaires were accompanied with the participant information sheets. This study was approved by the School of Pharmacy Ethics Board December 2018. The questions included both open and closed questions to obtain a more detailed insight into each participant's thoughts and experiences. Anxiety is a broad area with a particularly unique experience for each individual hence the definition of anxiety was given to allow a more accurate response.

\section{Findings}

There were more females (58\%) than males (40\%) who participated and $2 \%$ did not disclose their gender. Table 1 shows the age of participants. 
Table 1: The number of individuals and their respective ages, genders and the number of participants selected

\begin{tabular}{llll}
\hline Age group & Age selected & Female & Male \\
\hline $18-24$ & $38(76 \%)$ & $23(46 \%)$ & $15(30 \%)$ \\
$25-34$ & $9((18 \%)$ & $6(12 \%)$ & $3(6 \%)$ \\
$35-44$ & $3(6 \%)$ & 0 & $3(6 \%)$ \\
45 and over & 0 & 0 & 0 \\
\hline
\end{tabular}

The participants were from a range of ethnic groups, which provided some insight, and allowed interesting patterns to be recognised (table 2). There were $18 \%$ of participants chosen 'other', $15 \%$ were Arab and 3\% Sri Lankan. This question could have been designed better to include more options or broader ethnic backgrounds such as 'south-east Asian' as opposed to Pakistani or Indian, however, this option was not used to allow for more detailed backgrounds from which distinct patterns could be drawn. Students were asked if they have a paid job, $94 \%$ participants stated as being students with the remaining 6\% identifying as being 'Students/Employed'.

\section{What is anxiety?}

Option C 'a feeling of worry, nervousness or unease about something with an uncertain outcome', was selected by $100 \%$ of participants. The question used the anxiety definition according to Anxiety UK [3].

Table 2: The number of participants from each ethnic group

\begin{tabular}{lll}
\hline & Ethnic group & Number of participants \\
\hline A & White/Caucasian & $7(14 \%)$ \\
B & Black/Afro-Caribbean & $12(24 \%)$ \\
C & Pakistani & $13(26 \%)$ \\
D & Indian & $9(18 \%)$ \\
E & Chinese & $0(0 \%)$ \\
F & Other & $9(18 \%)$ \\
\hline
\end{tabular}

\section{What are the signs and symptoms of anxiety?}

This question intended to explore the symptoms of anxiety. Participants were asked to select all applicable options (fig. 1). Of note is that there were more options selected in every case for females than males, Options A, B, C, D and E were the most chosen options amongst all ethnic groups. However, Pakistan participants were consistently selecting most symptoms with option $\mathrm{D}$ as the most chosen option $(100 \%)$. Another similar pattern was seen in Black/Afro-Caribbean students with $100 \%$ selecting option B.

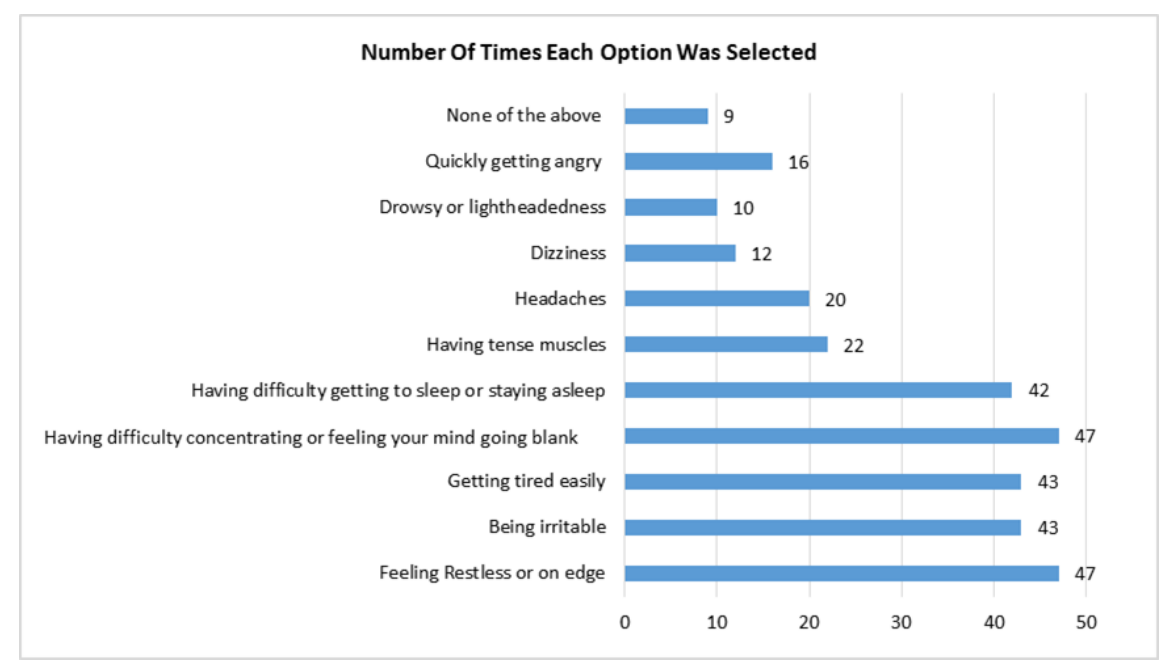

Fig. 1: The graph shows each option and how many times it was selected from all 50 participants Legend: A: Feeling restless or on edge, B: Being irritable, C: Getting tired easily, D: Having difficulty concentrating or feeling your mind goes blank E: Having difficulty getting to sleep or staying asleep or staying asleep F: Having tense muscles, G: Headaches, H: Dizziness I: Drowsy or lightheadedness J: Quickly getting angry K: None of the above

\section{What is cognitive behavioural therapy (CBT)?}

All participants chose the correct option that CBT is a 'type of talking treatment which focusses on how your thoughts, beliefs and attitudes affect your feelings and behaviour. 'This indicates a good level of knowledge about how anxiety is treated. However, the students are from a health programme (MPharm) and are expected to know. This might not represent the outcome for students in a non-medical programme. Additionally, when students were asked
'How is anxiety treated? Only $2 \%$ of participants selected incorrect option (other than option D).

What are the groups of medications, which can sometimes be used in the treatment of anxiety?

Table 3 is showing the options selected by participants. The most chosen option was benzodiazepines $(70 \%)$ and the most common combination of answers was SSRI and Benzodiazepines $(56 \%)$. 
Table 3: The table shows the number of participants who chose each respective drug

\begin{tabular}{lll}
\hline & Drug options & Number of time participants chosen \\
\hline A & Beta blockers & $6(12 \%)$ \\
B & Selective serotonin reuptake inhibitors & $7(14 \%)$ \\
C & Opioid painkillers & 0 \\
D & Ace inhibitors & 0 \\
E & Calcium channel blockers & 0 \\
F & Benzodiazepines & $35(70 \%)$ \\
G & Don't know & $2(4 \%)$ \\
\hline
\end{tabular}

\section{What are the side effects for the medication you chose?}

The correct options were'Sexual dysfunction (48\%)' and 'Suicidal feelings (40\%)' for SSRIs and benzodiazepine respectively. There were no significant patterns found according to gender, age or ethnic background. This question was designed to further understand whether participants were aware of the drugs side effects (fig. 2).

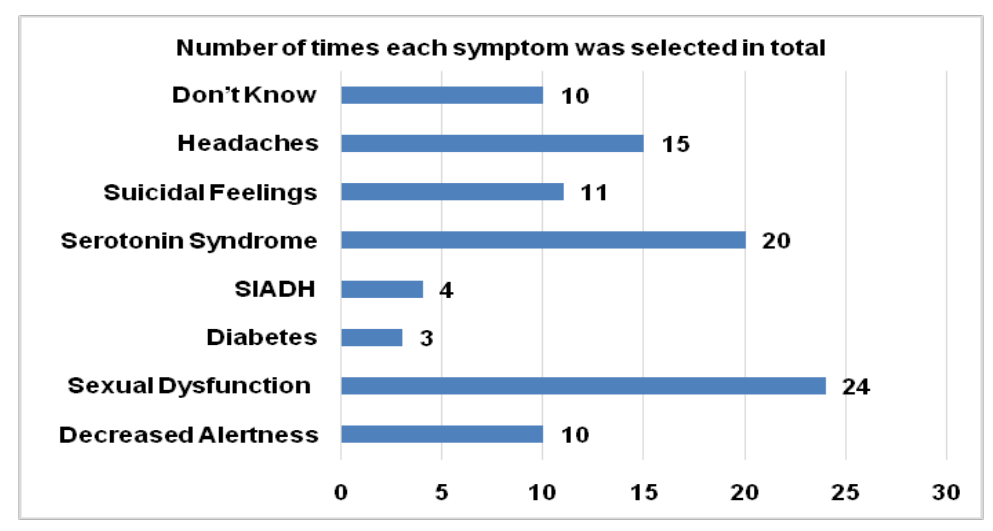

Fig. 2: Shows the side effect options and the number of times each side effect was selected

\section{Who can prescribe these drugs?}

The incorrect option was Psychologists as they do not have prescribing rights. Fig. 9 below illustrates the percentage of participants choosing each option (fig. 3).

\section{Percentage Of Each Option Was Selected}

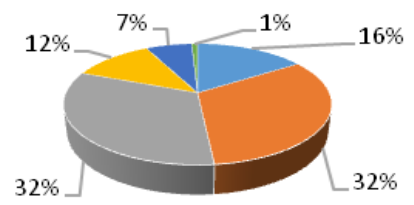

\author{
- Psychiatrist \\ - Independent Prescriber \\ Pharmacist \\ - Genereal Practioner
}

Fig. 3: Above shows the percentage of participants for each option

\section{Do you experience moments of anxiety?}

The data shows that most of these students are affected by anxiety $(84 \%)$. There were more females $(89 \%)$ than males $(74 \%)$ reported to be experiencing anxiety. Anxiety was worst in Pakistani (C) participants (92\%) stated that they experienced anxiety, followed by Black/AfroCaribbean (B) participants (91\%) and White/Caucasians (A) had the lowest (57\%) level of anxiety. Age group 18-24 had the most experience with anxiety $(68 \%)$ followed by $28-34(18 \%)$ and $35-44(6 \%)$.

\section{How do you feel when you are anxious or experience anxiety?}

This question provided the participant with symptoms which they may experience when that have anxiety episode based on the NHS web page (nhs. uk, 2019 (table 4). Options C (70\%), A (62\%), H $(52 \%)$ and $\mathrm{E}(50 \%)$ were the most selected by all age groups, genders and ethnic groups. The most chosen answer amongst males was being 'irritable' at $60 \%$. The lowest for males was equally between option $\mathrm{B}$ and option $\mathrm{F}$ which are being easily fatigued and having a headache $(15 \%)$. Option $\mathrm{C}$ was the highest option selected by females and J 'sweating/fast heartbeat' was the lowest (10\%). The highest symptom selected by 18-24 age group was 'restless or on edge' and 'irritability' (50\%) and the lowest was option J indicating 'fast heartbeat/sweating'. The highest for 25-34 age group was the same for options $\mathrm{C}$ and $\mathrm{E}(66 \%)$ and the lowest for the same age group was an option I (10\%). The highest option chosen was option C 'irritability' with more than $10 \%$ of every ethnicity and the lowest across all of the ethnic groups was option J 'sweating/fast heartbeat' (2\%).

Table 4: Selected options by frequency

\begin{tabular}{lll}
\hline Options & Statement & Option by frequency and percentage \\
\hline A & Restless or on edge & $31(62 \%)$ \\
B & Easily fatigued & $15(30 \%)$ \\
C & Irritable & $35(70 \%)$ \\
D & Muscle tension & $20(40 \%)$ \\
E & Difficulty to concentration & $25(50 \%)$ \\
F & Headache & $14(28 \%)$ \\
G & Excessive sleep & $19(38 \%)$ \\
H & Difficulty or unsatisfying sleep & $26(52 \%)$ \\
I & Heavy breathing & $14(28 \%)$ \\
J & Other & $11(22 \%)$ \\
\hline
\end{tabular}




\section{How often do you experience these episodes?}

This question aimed at obtaining data on the number of times each participant-experienced anxiety within set intervals provided to understand the frequency of experiences each participant has with anxiety (fig. 4). There were $37 \%$ of females indicating that they were affected 'sometimes, option B' as opposed to males of whom $80 \%$ selected 'rarely, option A', $13 \%$ of females stated that they experienced anxiety daily (option D). There were no significant differences between ethnic groups.

In your opinion, what are the triggers for your episodes of anxiety?

This question aimed to explore the factors that each participant would see as triggers for their anxiety episodes. Participants were asked to select all applicable options (table 5).

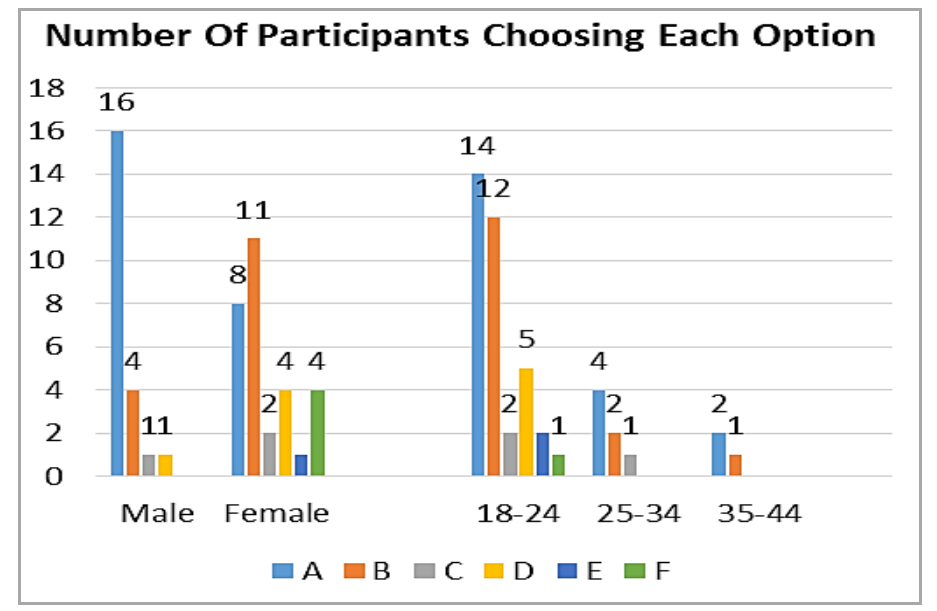

Fig. 4: Shows the number of times each option selected by age, gender and ethnicity Legend: A: Rarely, B: Sometimes, C: Weekly, D: Daily, E: Monthly, F: Always

Table 5: Table showing the number of times each option was chosen

\begin{tabular}{lll}
\hline Options & Answer & Options by frequency and percentage \\
\hline A & Work & 1 \\
B & University Lecture/lessons & 14 \\
C & University Exams & 41 \\
D & Case-Based Learning (CBL) & 15 \\
E & TBL Assessments & 18 \\
F & Family/Friends & 10 \\
G & Social Interactions & 10 \\
H & Relationships & 10 \\
I & Thinking About The Future & 10 \\
J & Submissions Deadlines & 18 \\
K & Overthinking In General & 27 \\
L & Other, Please state & 2 \\
\hline
\end{tabular}

Fig. 5 shows options selected by gender and age groups. There were no significant differences between ethnic groups.

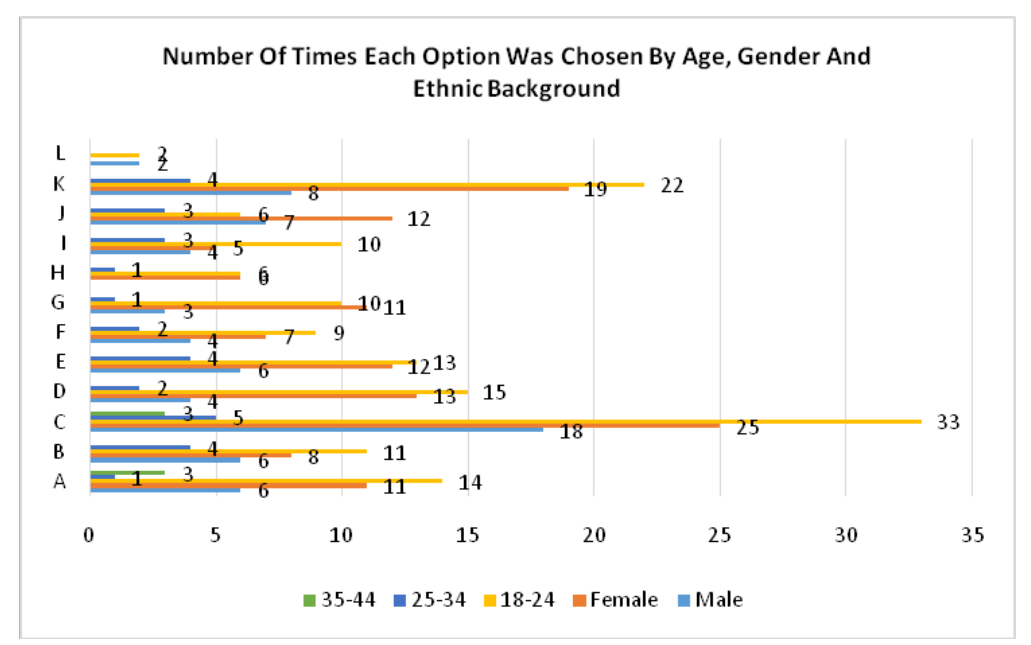

Fig. 5: Shows the number of times each option selected by age, gender and ethnicity 
In your opinion, have the episodes of anxiety been the same every time you experienced them or they change in severity?

Table 6 shows the number of times each option selected by frequency and percentage. This clearly shows that a large number of participants felt their anxiety got worse from sixth form/college and progressively worse as academic years increased from year 1 on the MPharm programme to year 4 , by selecting the combination of $\mathrm{B}, \mathrm{D}$ $\mathrm{F}$ and $\mathrm{H}$.

Table 6: Option frequency of selection and percentage

\begin{tabular}{|c|c|c|}
\hline Options & Answers & Number of times options each chosen \\
\hline $\mathrm{A}$ & Better Than Sixth-Form/College & $6(12 \%)$ \\
\hline $\mathrm{B}$ & Worse Than Sixth-Form/College & $34(68 \%)$ \\
\hline $\mathrm{C}$ & Better Than $3^{\text {rd }}$ Year MPharm & $4(8 \%)$ \\
\hline $\mathrm{D}$ & Worse Than $3^{\text {rdYear MPharm }}$ & $23(46 \%)$ \\
\hline $\mathrm{E}$ & Better Than $2^{\text {nd }}$ Year MPharm & $2(4 \%)$ \\
\hline $\mathrm{F}$ & Worse Than $2^{\text {nd }}$ Year MPharm & $23(46 \%)$ \\
\hline $\mathrm{G}$ & Better Than $1^{\text {st }}$ Year MPharm & $0(0 \%)$ \\
\hline $\mathrm{H}$ & Worse Than $1^{\text {st }}$ Year MPharm & $26(52 \%)$ \\
\hline I & No changes, I cannot Tell & $8(16 \%)$ \\
\hline $\mathrm{J}$ & Other, Please State & $0(0 \%)$ \\
\hline
\end{tabular}

More females selected combination of B, D, F and Hthan males and in younger than older students (fig. 6, 7 and 8).

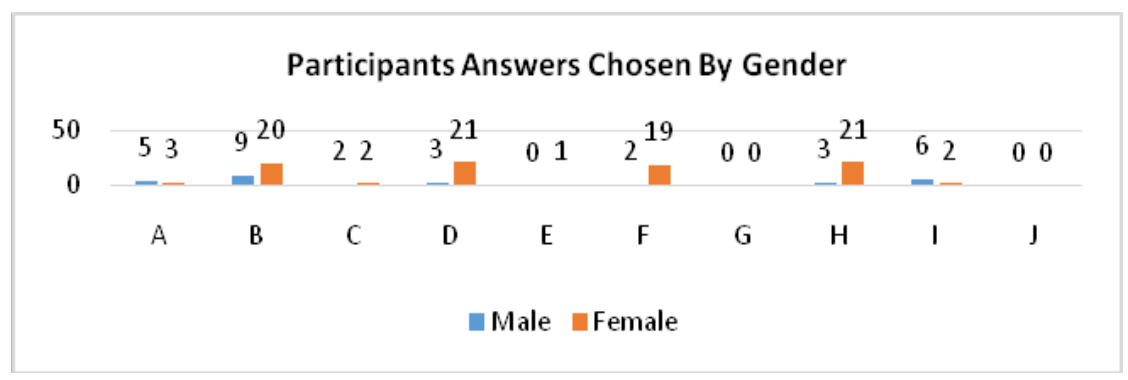

Fig. 6: Shows the number of times each option selected by gender

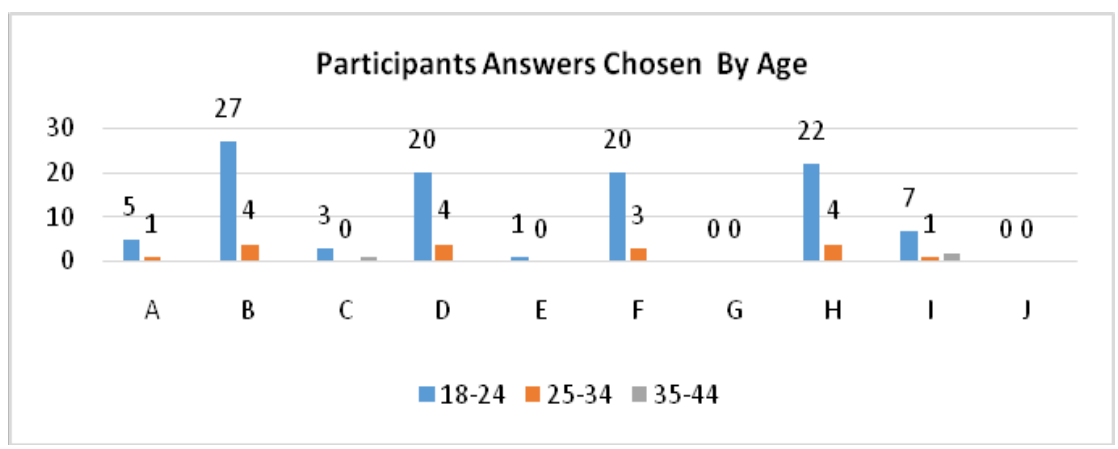

Fig. 7: Shows the number of times each option selected by age

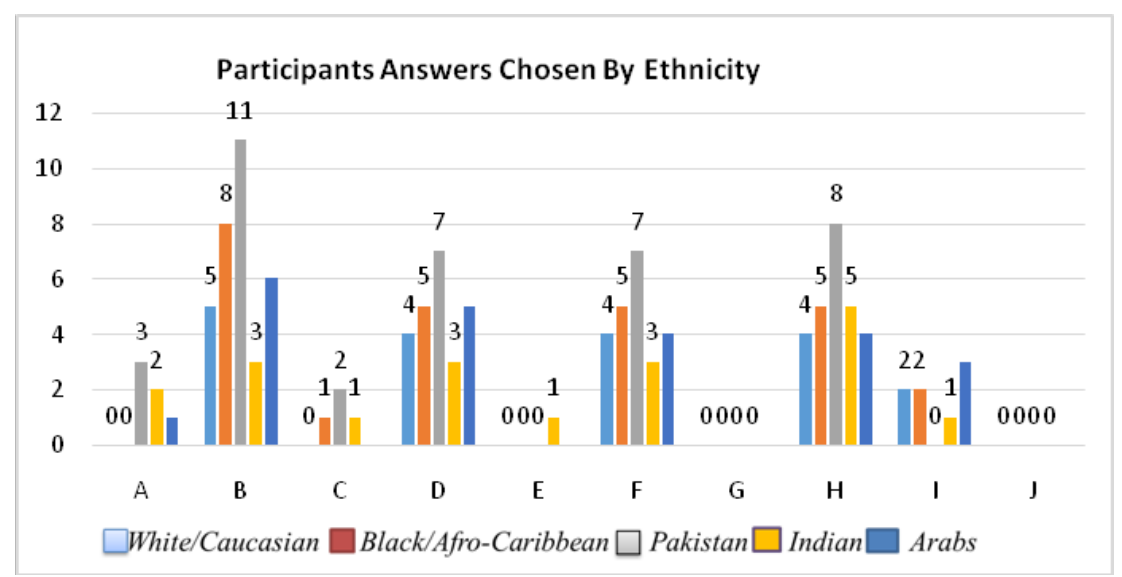

Fig. 8: Shows the number of times each option selected byethnicity 
Table 7: Shows the number of times each option chosen by participants

\begin{tabular}{lll}
\hline Options & Answers & Number of times chosen \\
\hline A & Never Affected My Grade And Achievements & $5(10 \%)$ \\
B & Only Affected My Grades And Achievements When I Experienced It For The First Time & $7(14 \%)$ \\
C & Anxiety Affects My Grades All The Time & $18(36 \%)$ \\
D & Only When I Have To Present & $5(10 \%)$ \\
E & Only When There Is A Written Exam & $11(22 \%)$ \\
F & Only When I Have To Work With People & $5(10 \%)$ \\
G & Only When I Submit An Assessment Item & $2(4 \%)$ \\
H & Combination Of (Please Write The Numbers) & $1(2 \%)$ \\
I & I Don't Know & $2(4 \%)$ \\
\hline
\end{tabular}

Females and males both chose option C (anxiety affects my grades all the time) the most with $35 \%$ of males and $37 \%$ of females. There was no significant difference between age group and ethnicity.

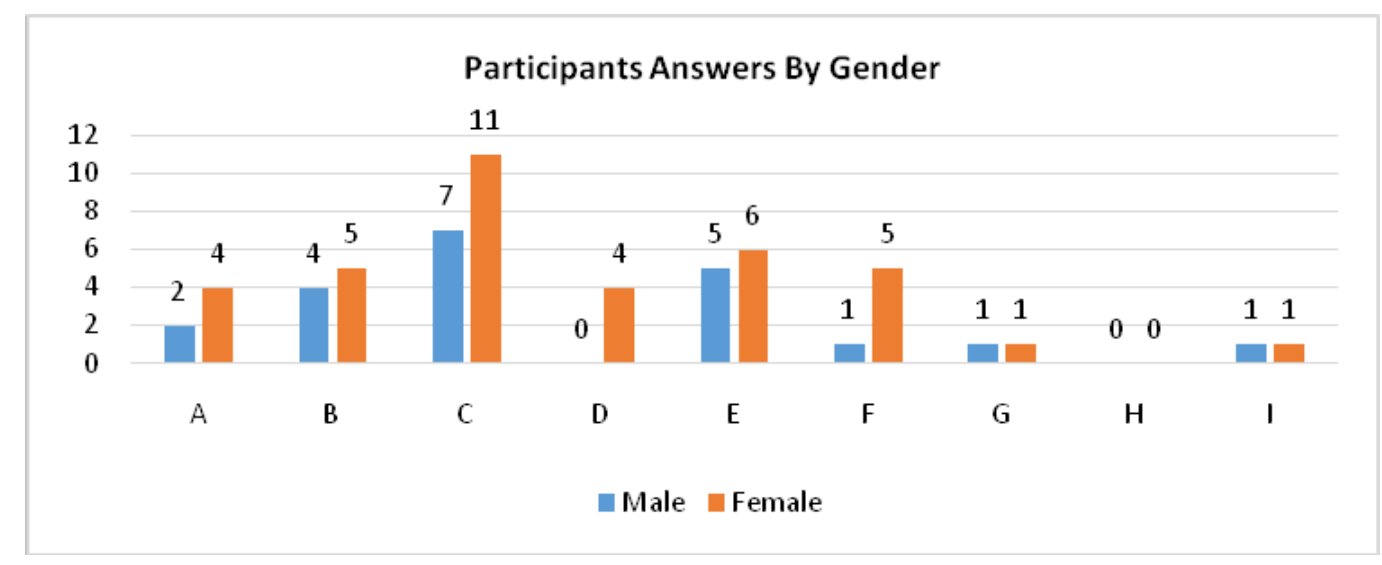

Fig. 9: Graph showing the number of times each option selected by gender

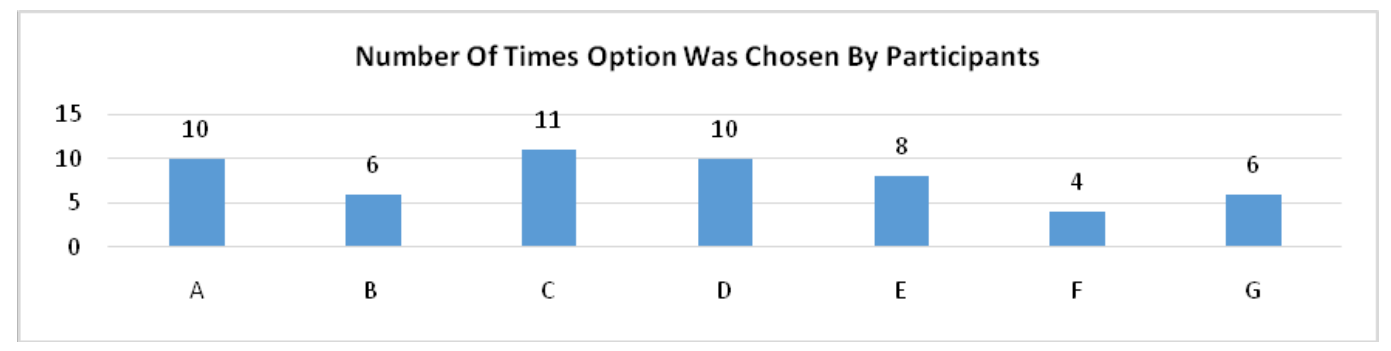

Fig. 10: Shows a bar chart illustrating the number of times each option selected by participants

Legend: A: Yes, they know at home, B: Yes, they know at university students services, C: Yes, my friends know, D: No, I have not told anyone at home, E: No, I have not told anyone at the university, F: No, I have not told any of my friends, G: I don't have anxiety

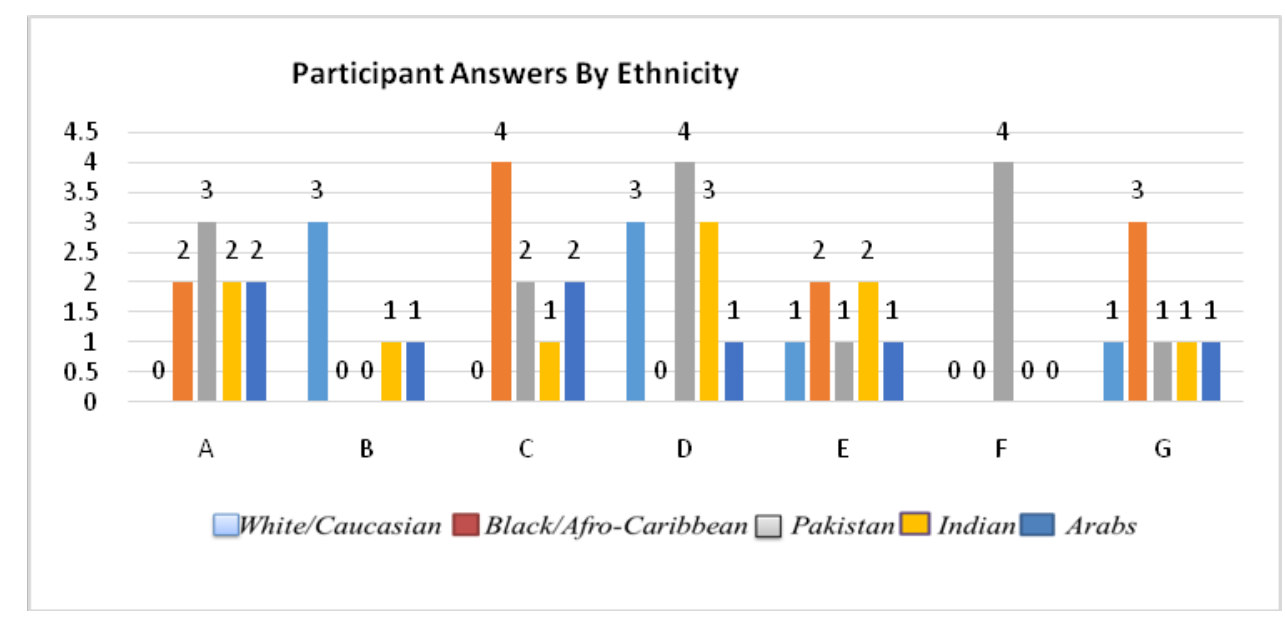

Fig. 11: Shows the number of times each option chosen by ethnicity 
What is the impact, if any, of anxiety episodes you have experienced on your grades and achievements?

This question aimed to provide information on how anxiety was affecting academic success.

Have you told anyone at home or university about your anxiety to accommodate your needs?

This question was especially important to ask to identify what framework and infrastructure is currently in place for students that they are aware of that they can refer to when they need assistance and help. Fig. 10 illustrate the number of times each option selected.

All options were selected by more females than males, except for option $\mathrm{G}$ was selected by more males than females $(12 \%$ and $2 \%$ respectively). There was no significant difference between age groups. Fig. 11 showing results by ethnicity.

\section{Why have you not told anyone?}

The fig. 12 illustrates the number of times each option chosen by age, gender and ethnicity.

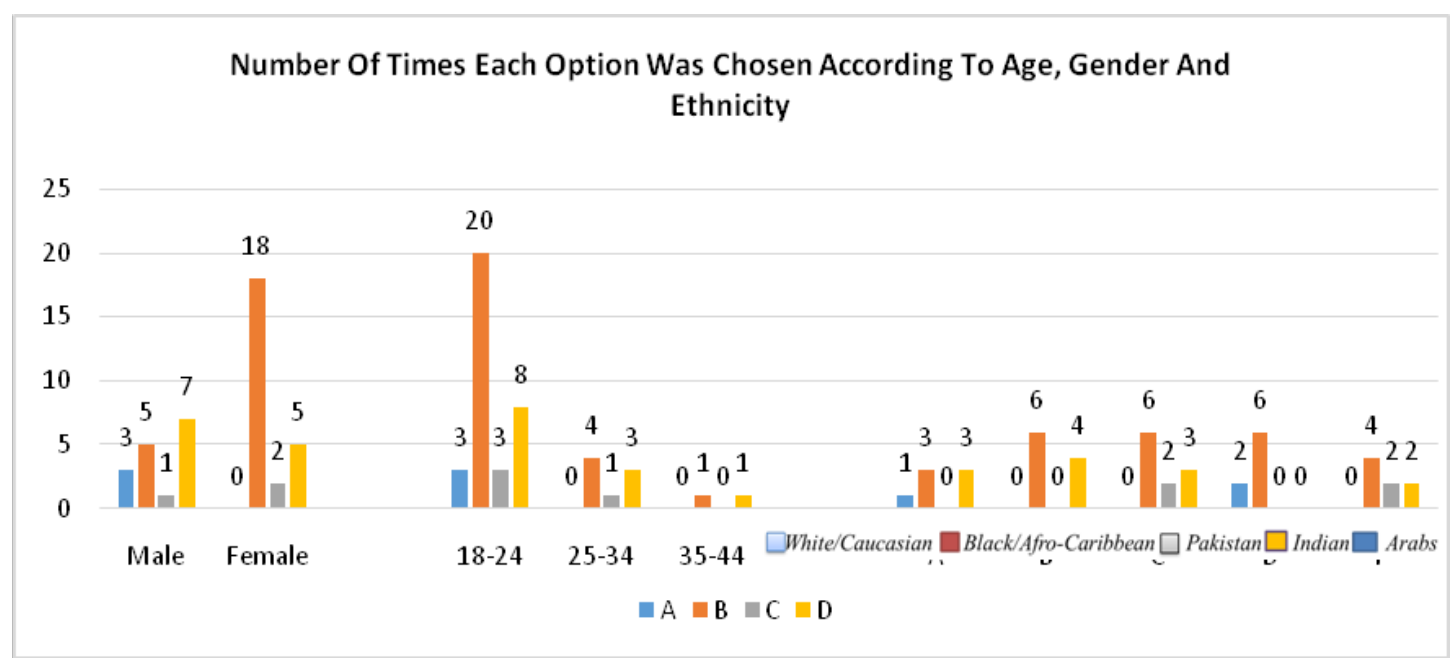

Fig. 12: Shows the number of time each option selected by age, gender and ethnicity

Legend: A: I don't think anyone cares, B: I don't think anyone needs to know, C: I don't think I can share it, D: Other, please state

Furthermore, ethnic groups including the Black/Afro-Caribbean's, Indians and Pakistanis all showed a higher inclination to hide their anxiety and not share it as opposed to White/Caucasians.

\section{Do you have any other comments?}

This was an open-ended question with a space provided for the participant to fill in with their thoughts. Few participants provided a response.

- $\quad$ 'We need more research to find treatment' (participant 1).

- 'We need better level of awareness and management options for students within the university/higher education sector' (Participant 2).

- 'We need verbal discussion rather than questionnaires to understand the reasons behind each participant's anxiety' (participant 3).

\section{DISCUSSION}

This research intended to explore anxiety in a group of higher education students and examine the effects that anxiety has on students, the factors that can influence anxiety, how detrimental those effects are and how individual factors such as ethnicity, age and gender may positively or negatively affecting student's anxiety.

The study found that anxiety is presently affecting more females $(89 \%)$ than males $(74 \%)$ in the MPharm. Considering that in courses such as pharmacy there are more females than males enrolled, the finding suggests that anxiety is affecting more students in this course than not, which agrees with Andrews and Wilding ${ }^{8}$. Our responses supported this study hypothesis, where $87 \%$ of participants stated their anxiety is worse now than when at sixthform/college. The trend of worsening anxiety was reported as from year 1 to $2(59 \%)$ and from year 2 to $3(54 \%)$ which is similar the findings ofInam ${ }^{6}$ and Mackaskill ${ }^{4}$; students were increasingly anxious especially at the mid-point of the course (59\%).
The frequency of anxious episodes is particularly important in examining the extent to which anxiety is affecting a student's performance academically. Out of all participants $80 \%$ of males stated they experienced anxious episodes 'rarely' whereas $37 \%$ of females stated episodes to be rare indicating that less males were affected compared to females. A similar trend found when exploring frequencies, $13 \%$ of females experienced anxiety daily compared to $5 \%$ of males. This was further reinforcing current statistics published by the Office for National Statistics [10] that females are more likely to be affected by anxiety than males and Martín-Merino [11], who concluded that women are as twice as likely to suffer from anxiety compared to men.

Another objective of this study was to identify triggers and the frequency of anxiety; examinations were the highest trigger (82\%). Interestingly, triggers such as family/friends, relationships and social interactions were the lowest chosen triggers with $20 \%$ of participants listing it as a trigger. This is in direct contradiction with Russell and Shaw ${ }^{5}$, who concluded that social factors such as family and relationships accounted largely for anxiety in students at university. However, $54 \%$ of participants listed 'overthinking in general' as a trigger, this option was relatively vague as overthinking can be about anything including family issues and financial problems.

White/Caucasians were the smallest group (14\%), 57\% stated they experienced anxiety; however, this cannot be generalized due to the small sample size. Pakistani participants constituted $26 \%$ of all participants with $100 \%$ stated they experience anxiety; followed by Black/Afro-Caribbean (91\%), Arabs and Indians (66\% each). These fig. conform to the Office for National Statistics [10], where ethnic groups generally had a higher anxiety score compared to White/Caucasians population.

\section{CONCLUSION}

Assessing the impact of anxiety on student's academic performance is vital. When participants were asked to describe how anxiety affected their academic performance, the most selected option was 
'anxiety affects my grades all the time' by $36 \%$ of participants and $22 \%$ of participants stating that anxiety affects them in the event of a written exam only. These findings only suggest that further research is imperative to conceptualize the true scale to the problem and for suitable solutions to in order to understand the growing problem of mental health in students. As with previous literature, recommendations to higher education's institutions would be the need for more research into the area of anxiety and how it they can provide services to accommodate student's needs.

\section{LIMITATION}

The use of a survey carried multiple advantages and limitations however; it generated sufficient data to analyse. A cross-sectional study would have provided more in-depth insight into how students in each year of study were affected by obtaining comparable values as opposed to the single-survey approach depending on the students recalling feelings they have experienced in the past. The option of financial problems was not included in the list of triggers, which requires more investigation as recommended by Andrews and Wilding, (2004) who concluded that 'financial difficulties made a significant independent contribution to depression and anxiety'. Screening on participant's anxiety before they started university was not possible to consider, however, should be considered in future research. Marital status and accommodation arrangement were not considered, which further limit the results application to the general students population.

\section{AUTHORS CONTRIBUTIONS}

All the author have contributed equally

\section{CONFLICT OF INTERESTS}

Declare none

\section{REFERENCES}

1. Who. Int. WHO | Mental disorders affect one in four people; 2019. Available from: https://www.who.int/whr/2001/ media_centre/press_release/en/ [Last accessed 22 Mar 2019].
2. Mental Health Foundation. Mental health statistics: anxiety; 2019. Available from: https://www.mentalhealth.org.uk/ statistics/mental-health-statistics-anxiety. [Last accessed 23 Jan 2019].

3. Anxiety UK. Statistics-anxiety UK; 2019. Available from: https://www.anxietyuk.org.uk/get-help/anxietyinformation/frequently-asked-questions [Last accessed on 25 Feb 2019].

4. Mackaskill A. The mental health of university students in the United Kingdom. Br J Guidance Counselling 2013;41:426-41.

5. Russell G, Shaw S. A study to investigate the prevalence of social anxiety in a sample of higher education students in the United Kingdom. J Mental Health 2009;18:198-206.

6. Inam SN, Saqib A, Alam E. Prevalence of anxiety and depression among medical students of the private university. J Pakistan Med Assoc 2003;53:44-7.

7. Bayram N, Bilgel N. The prevalence and socio-demographic correlations of depression, anxiety and stress among a group of university students. Soc Psychiatry Psychiatric Epidemiol 2008;43:667-72.

8. Andrews B, Wilding J. The relation of depression and anxiety to life-stress and achievement in students. $\mathrm{Br} \mathrm{J}$ Psychol 2004;95:509-21.

9. Hospital Anxiety and Depression Scale (HADS); 2018. Available from: https://www.gl-assessment.co.uk/products/hospitalanxiety-and-depression-scale-hads/ [Last accessed on $08 \mathrm{Mar}$ 2019].

10. Office f.or National Statistics. Well-being: anxiety yesterday. Ethnicity-facts-figures.service.gov.uk; 2018. Available from: https://www.ethnicity-facts-figures.service.gov.uk/health/ physical-and-mental-health/well-being-anxiety-yesterday/ latest [Last accessed on 27 Feb 2019]

11. Martín Merino E, Ruigomez A, Wallander MA, Johansson S, Garcia Rodriguez LA. Prevalence, incidence, morbidity and treatment patterns in a cohort of patients diagnosed with anxiety in UK primary care. Family Practitioner 2010;27:916. 